Published in final edited form as:

Dement Geriatr Cogn Disord. 2016 ; 41(1-2): 80-92. doi:10.1159/000441139.

\title{
Effect of Amyloid Imaging on the Diagnosis and Management of Patients with Cognitive Decline: Impact of Appropriate Use Criteria
}

\author{
Michael Grundman ${ }^{\mathrm{a}, \mathrm{b}}$, Keith A. Johnson ${ }^{\mathrm{c}}$, Ming Lu ${ }^{\mathrm{d}}$, Andrew Siderowf ${ }^{\mathrm{d}}$, Grazia \\ Dell'Agnello $^{e}$, Anupa K. Arorad, Daniel M. Skovronsky ${ }^{d}$, Mark A. Mintun ${ }^{d}$, and Michael J. \\ Pontecorvod ${ }^{18}$ F-AV-45-A17 Study Group \\ aGlobal R\&D Partners, LLC, and University of California, San Diego, Calif. \\ bDepartment of Neurosciences, University of California, San Diego, Calif. \\ 'Massachusetts General Hospital, Harvard Medical School, Boston, Mass. \\ ${ }^{\mathrm{d}}$ Avid Radiopharmaceuticals, Inc., Philadelphia, Pa., USA \\ eEli Lilly and Company, Florence, Italy
}

\begin{abstract}
Background-Published appropriate use criteria (AUC) describe patients for whom amyloid positron emission tomography (PET) might be most useful. This study compared the impact of amyloid PET on diagnosis and management in subjects likely to either meet or not meet AUC.

Methods-Physicians provided a provisional diagnosis and management plan for patients presenting with cognitive decline before and after amyloid PET imaging with florbetapir F 18. Participants were classified as AUC-like or not, based on the prescan diagnosis and demographic features.
\end{abstract}

Results-In all, 125 of 229 participants (55\%) were classified as AUC-like. Sixty-two percent of the AUC-like subjects had a change in diagnosis after scanning compared with $45 \%$ of the nonAUC subjects $(\mathrm{p}=0.011)$. Both groups demonstrated high rates of change in their management plans after scanning (88.0\% for AUC-like cases, $85.6 \%$ for non-AUC cases).

Conclusions-The impact of amyloid imaging on diagnosis and planned management was maintained and, if anything, amplified in AUC-like patients.

Michael J. Pontecorvo, PhD, Avid Radiopharmaceuticals, Inc. 3711 Market Street, Philadelphia, PA 19104 (USA), pontecorvo@avidrp.com.

Disclosure Statement

Michael Grundman has been a paid consultant to Avid Radiopharmaceuticals. Keith A. Johnson has been a principal investigator for the Massachusetts General Hospital site in clinical trials sponsored by Avid Radiopharmaceuticals. Ming Lu, Andrew Siderowf, Daniel M. Skovronsky, Mark A. Mintun, and Michael J. Pontecorvo are employees of Avid Radiopharmaceuticals, a wholly owned subsidiary of Eli Lilly and Company, and Grazia Dell'Agnello is an employee of Eli Lilly and Company, makers of florbetapir. Members of the ${ }^{18}$ F-AV-45-A17 Study Group are listed in the Appendix. 


\section{Keywords}

Florbetapir; Amyloid imaging; Positron emission tomography; Appropriate use criteria; Alzheimer's disease

\section{Background}

Despite nearly 30 years of evolution in clinical diagnostic criteria [1,2], early and accurate diagnosis of Alzheimer's disease (AD) remains an elusive target. Recent evaluations of autopsy outcomes of patients diagnosed by top experts at US Alzheimer's Disease Research Centers indicated that nearly $20 \%$ of patients clinically diagnosed as having probable AD in life did not meet criteria for AD pathology at autopsy, while more than $40 \%$ of patients diagnosed as having non-AD dementia had histopathologically defined $\mathrm{AD}[3,4]$.

The advent of positron emission tomography (PET) imaging agents such as Pittsburgh compound B [5], ${ }^{18} \mathrm{~F}$-florbetaben [6], ${ }^{18} \mathrm{~F}$-flutemetamol [7], and florbetapir F 18 [8, 9], which bind to fibrillar $\beta$-amyloid (A $\beta$ ), has made it possible to estimate, in living patients, the density of neuritic amyloid plaques [10-14]. Because neuritic plaques are a required component of a pathological diagnosis of AD, PET-derived information regarding neuritic plaque density could be of value in the diagnosis of patients with cognitive impairment. Multiple studies have now investigated the impact of amyloid PET imaging on diagnostic decision-making [15-21], demonstrating that PET imaging information could lead to changes in diagnosis and diagnostic confidence. Further, the study by Grundman et al. [17] demonstrated a change in intended management by study physicians in $87 \%$ of cases.

The patients selected for the studies above ranged from participants in a phase 2 clinical trial [21] to patients in clinical settings $[16,18,19]$. The study population used by Grundman et al. [17] was designed to encompass what was, at that time, expected to be the likely population to receive amyloid PET once an agent was approved, i.e., patients undergoing or having recently completed evaluations for cognitive decline in clinical settings for whom there remained diagnostic uncertainty. Subsequently, consensus criteria for the appropriate use of amyloid imaging agents [appropriate use criteria (AUC)] have been developed jointly by the Society for Nuclear Medicine and Molecular Imaging and the Alzheimer's Association amyloid imaging taskforce (AIT) [22]. Specifically, these criteria suggest that amyloid PET imaging is appropriate for subjects with an objectively confirmed cognitive complaint and satisfying criteria for possible $\mathrm{AD}$ with an uncertain diagnosis after an evaluation by a dementia expert. Three types of patients are noted for whom such use might be appropriate: those with persistent unexplained mild cognitive impairment (MCI), those satisfying core criteria for possible $\mathrm{AD}$ with unclear clinical presentation, and those with dementia and atypically early onset. Similar criteria have also been proposed by the Royal College of Physicians and Royal College of Radiologists (RCP-RCR) [23] and by the Italian Interdisciplinary Working Group (IIWG) [24].

The present study reevaluated the results of Grundman et al. [17] in light of the published AUC. Case records from that study were evaluated, and each patient was designated as having a profile consistent with the AUC (AUC-like) or potentially inconsistent with the 
criteria (non-AUC). The impact of PET scan information was evaluated separately in these populations.

\section{Methods}

This report presents an additional analysis of data acquired prospectively in a prior study designed to examine the impact of an amyloid PET scan on intended patient management [17]. No new patients were enrolled, and no patient procedures were performed. The previous study was registered at https://clinicaltrials.gov/(NCT01400425) and was conducted according to the International Committee on Harmonization-Good Clinical Practice and all applicable laws and regulations. All relevant institutional review boards approved the study.

The methods and results of the previous study are detailed in another report [17]. Briefly, the study enrolled 229 subjects, 110 of whom had completed a diagnostic workup for progressive cognitive decline within the previous 18 months, with no further tests planned or deemed relevant (group A); 119 were still undergoing evaluation (group B) but had advanced to a point where the investigator believed an amyloid PET scan might be useful. For inclusion of a patient in either group, the investigator had to have less than $85 \%$ confidence in the diagnosis at the time of enrollment, with at least $15 \%$ certainty that $\mathrm{AD}$ pathology might be contributing to the cognitive impairment.

After obtaining informed consent and conducting a baseline visit, but prior to ordering the PET scan, physicians recorded the current working diagnosis for each subject by selecting from a list of options, including: (1) etiology due to $\mathrm{AD}$ (most likely etiology is $\mathrm{AD}$, e.g., probable $\mathrm{AD}$, atypical $\mathrm{AD}$, Lewy body disease with $\mathrm{AD} /$ amyloid pathology, or mixed dementia with $\mathrm{AD}$; prodromal $\mathrm{AD}$ or $\mathrm{MCI}$ due to $\mathrm{AD}$ ); (2) non-AD etiology (most likely etiology is not $\mathrm{AD}$, e.g., vascular dementia, frontotemporal dementia; Lewy body disease without $\mathrm{AD}$ pathology; primary progressive aphasia; metabolic, psychiatric, or medicationinduced impairments, or impairment of uncertain etiology but not due to AD), or (3) indeterminate (syndromic) etiology (e.g., progressive cognitive decline, MCI, or dementia of uncertain etiology). The treating physicians were asked to provide a diagnostic testing and management plan, again selecting from a list of options, using only information available before florbetapir imaging, as if a florbetapir PET scan were not to be performed, e.g., initiation/withdrawal of medications, ordering additional diagnostic tests, referral to another specialist, explanation of diagnosis, and advice regarding potential safety concerns.

Subjects were imaged with florbetapir PET (10 min acquisition beginning $50 \mathrm{~min}$ after an intravenous administration of $370 \mathrm{MBq}$ florbetapir) within 30 days of completion of the baseline screening visit, as described previously. Additional diagnostic tests were not permitted during this interval. The scan result (amyloid positive or amyloid negative as determined by an expert reader, M.A.M. or A.K.A., in accordance with visual interpretation instructions in the florbetapir package insert) was then transmitted to the site physician, who recorded a revised clinical diagnosis and proposed treatment plan, this time taking into account the florbetapir PET scan results along with all other information. 
The diagnosis and intended management at baseline were compared to those obtained after revealing the florbetapir PET scan result. In the original study, analyses were performed across all subjects, and separately for subjects in groups A and B, for amyloid-positive and negative subjects and for demented and nondemented subjects. The present study extends these analyses to subjects having a profile consistent with the AUC guidelines (AUC-like) or inconsistent with the guidelines (non-AUC). The primary goal was to determine whether the conclusions of the study by Grundman et al. [17] - specifically, that amyloid PET imaging results influenced diagnosis, planned management, and treatment - hold in the more narrowly defined AUC population.

\section{Classification of Cases as AUC-Like or Non-AUC}

The entry criteria for our previous study were similar in intent to the AIT-AUC guidelines, selecting for difficult-to-diagnose patients for whom some diagnostic uncertainty existed on the part of the reporting physician. However, because the study preceded the publication of the AUC, a retrospective analysis of the information recorded in the case records was required for an appropriate AUC classification, as shown in table 1. When there was any doubt as to whether to include ambiguous cases as AUC-like or not, we applied the most restrictive interpretation of the AUC as follows:

1. The AUC exclude patients in whom a cognitive complaint is not confirmed by objective impairment on clinical examination. The entry criteria for our prior study [16] required only evidence of progressive cognitive decline which could have been met by objective evidence or clinical history. Thus, some patients might have been enrolled on the basis of declining cognitive function, but they might have been classified as having no objective evidence of cognitive impairment (e.g., patients with high premorbid intelligence, within normal range on cognitive tests). Such subjects were classified as non-AUC for the current analysis.

2. Subjects in our study who were impaired but not demented (i.e., MCI), and with a symptom duration $>6$ months (i.e., persistent), were classified as AUC-like unless their impairment had been assigned a clear etiology (e.g., prodromal AD, $\mathrm{MCI}$ due to $\mathrm{AD}$, or probable $\mathrm{AD}$ etiology, or an $\mathrm{MCI}$ with a specific non- $\mathrm{AD}$ etiology), in which case they were not considered 'unexplained' MCI and were classified as non-AUC.

3. The AUC include patients who meet the core clinical criteria for possible AD, characterized by an unclear clinical presentation, either an atypical clinical course or etiologically mixed presentation, but exclude patients that meet the more stringent criteria for probable AD with a typical age at onset. All patients in our study had, at least to some degree, an unclear clinical presentation ( $<85 \%$ diagnostic certainty). However, the physicians were asked to provide a working diagnosis, which included the choice 'cognitive impairment with etiology due to $\mathrm{AD}$, i.e., probable $\mathrm{AD}$ or dementia of the Alzheimer's type'. Subjects receiving a working diagnosis of etiology due to $\mathrm{AD}$, further categorized as 'probable $\mathrm{AD}$ ' were classified as non-AUC for the current analysis. In contrast, subjects receiving a working diagnosis of etiology due to $\mathrm{AD}$ with atypical $\mathrm{AD}$, Lewy 
body disease with $\mathrm{AD}$, or mixed or vascular dementia with $\mathrm{AD}$ were classified as AUC-like.

4. All patients in our study had $\mathrm{AD}$ as a possible differential diagnosis/etiology ( $\geq 15 \%$ certainty of $\mathrm{AD}$ ). Thus, even subjects with a non-AD working diagnosis could be considered to meet the criterion for possible AD. Nevertheless, in order to conduct the most conservative analysis, subjects with a working diagnosis of non-AD etiology were classified as non-AUC, unless they were less than 65 years of age or were believed to have a mixed type of dementia that could also include AD.

5. The AUC indicate that an amyloid PET scan is appropriate for subjects with progressive dementia under the age of 65 years. All demented subjects under the age of 65 years were classified as AUC-like regardless of the diagnosis. Nondemented subjects under the age of 65 years were not automatically classified as AUC-like, unless they otherwise met the criteria above.

The AUC further require that cases be evaluated by experts with training and experience in the evaluation and care of patients with dementia. The most recent update of the AUC suggest an expert be defined as a physician that spends at least $25 \%$ of patient contact time in the evaluation and care of patients with dementia. We did not collect data on the percentage of time our referring clinicians spend with dementia patients. However, the clinicians at all 19 sites were neurologists, psychiatrists, or geriatricians experienced in clinical trials involving AD patients; at 13 centers, the clinicians had academic appointments, at 11 they had been authors of peer-reviewed publications on the topic of AD or cognitive impairment, and at 10 the clinical investigators had completed relevant specialized fellowship training. Thus, these clinicians appear to fit the broad concept of dementia experts, and no adjustment for site/clinician experience was made.

The RCP-RCR guidelines and the IIWG recommendations are essentially the same as the AIT-AUC, except that the AIT-AUC do not specifically recommend an order of tests, instead cautioning that the expert should evaluate all available clinical evidence (which could include structural imaging and other tests), whereas the RCP-RCR and IIWG guidelines specifically call for structural/conventional imaging to be performed prior to consideration of amyloid imaging. Thus, as a secondary analysis we separately evaluated the subset of the AUC cohort that had previously undergone MRI or CT procedures.

\section{Statistical Methods}

Descriptive statistics, means and standard deviations for continuous variables, and counts and proportions for categorical variables were applied to describe the characteristics of the study population and to describe the changes in physicians' diagnostic thinking and intended management after receiving florbetapir scan information between the AUC-like and nonAUC groups. Fisher's exact test (two-sided nominal significance level of 0.05) was applied to compare the significance of change in physicians' diagnostic thinking and intended management after receiving florbetapir scan information between the AUC-like and nonAUC groups. Due to the exploratory nature of this analysis, other comparisons were performed without statistical testing. 


\section{Results}

Table 1 shows the breakdown of diagnoses assigned to either the AUC-like or the non-AUC category. Note that the majority of patients (78\%) in the AUC-like group were given a syndromic diagnosis (diagnosis of uncertain etiology, not ascribed to AD, or non-AD pathology), while the majority of patients in the non-AUC group (63\%) were given a working diagnosis of impairment due to $\mathrm{AD}$. Table 2 shows the demographics for the subjects classified as AUC-like and non-AUC. Subjects in the AUC-like group comprised $55 \%(125 / 229)$ of the study sample. The baseline characteristics were similar between the two groups, except for prescan diagnosis.

The proportion of subjects having previously completed a workup (group A) at study entry was similar ( $\mathrm{p}=0.232)$ for the AUC-like $(65 / 125 ; 52 \%)$ and the non-AUC group $(45 / 104$; $43 \%)$. The proportion with previously completed workups was also similar among subjects with an indeterminate etiology $(53 / 122 ; 43 \%)$ compared to those ascribed specifically to an $\mathrm{AD}$ or non-AD etiology $(57 / 107 ; 53 \%)$. As expected, the diagnostic test frequencies before scanning were lower for group B than for group A subjects, with fewer than half of those in group B having undergone neuropsychological testing and structural brain imaging at study entry compared to the majority of group A subjects (online suppl. table 1; for all online suppl. material, see www.karger.com/doi/10.1159/000441139).

The likelihood of testing positive on florbetapir scanning was similar $(\mathrm{p}=0.509)$ for AUClike (47\%) and non-AUC subjects (52\%), but AUC-like subjects had a significantly higher rate of change in diagnostic thinking compared to non-AUC subjects (62 vs. $45 \%, p=0.011$; table 3; online suppl. table 2). For both AUC-like and non-AUC subjects, when the diagnosis changed it was in a direction to be consistent with the scan result, i.e., towards a diagnosis of $\mathrm{AD}$ after a positive scan and away from a diagnosis of $\mathrm{AD}$ after a negative scan.

Overall, both the AUC-like and non-AUC cohorts demonstrated high rates of change in their management plans after scanning ( $88 \%$ for AUC-like cases, $86 \%$ for non-AUC cases; $\mathrm{p}=$ 0.69 ; online suppl. table 3 ). This high overall rate of management change was partly due to the inclusion of 'explanation of diagnosis and advice regarding potential safety concerns' in the management composite outcome variable. Almost all patients received this counseling after disclosure of the PET scan results to the physicians.

However, an evaluation of the other testing and management items in the composite revealed that following disclosure of PET scan amyloid status results, changes in diagnostic testing were planned for a modestly greater proportion across all subjects in the AUC-like cohort than in the non-AUC cohort, for example, with respect to neuropsychological testing (25 vs. $20 \%$ ), brain structural imaging (16 vs. $12 \%$ ), and lumbar puncture (13 vs. $8 \%$ ). Changes in planned prescriptions of AD medication in the direction of the PET scan result (e.g., removal of medication after a negative scan) occurred nearly twice as often in the AUC-like as in the non-AUC cohort ( 25 vs. $13 \%$ ). However, in both cohorts the changes in intended medication use were in the direction of the scan result, and the difference in the proportion of intended $\mathrm{AD}$ medication prescription in $\mathrm{A} \beta+$ versus $\mathrm{A} \beta$ - subjects was comparable in the two cohorts (table 4). 
In group A patients, who had completed a full workup and had no additional diagnostic tests planned prior to florbetapir PET scanning, changes in management were limited primarily to changes in explanation of diagnosis and prescription of AD medications. However, management plan changes in group B patients, who had had an incomplete workup prior to the florbetapir scan, were more pronounced than in group A patients after scanning in both the AUC-like (98 vs. $78 \%$ ) and the non-AUC cohort (92 vs. 78\%). An examination of individual components of the composite for group B patients suggested modestly greater changes in the AUC-like cohort than in the non-AUC cohort with respect to ordering of neuropsychological testing (45 vs. 34\%), brain structural imaging (32 vs. 20\%), and lumbar puncture (23 vs. $10 \%$ ). Whereas both positive and negative scan results led to net reductions in planned neuropsychological testing, structural imaging, and lumbar puncture, there was a net increase in planned prescription of $\mathrm{AD}$ medications and referrals to $\mathrm{AD}$ clinical trials after positive scan results, and a net decrease (opposite effect) after negative scan results (fig. 1; online suppl. table 4).

Structural imaging (MRI or CT) was performed prior to amyloid PET in 154 of the 229 study subjects, including 93 of the 125 AUC-like subjects. The pattern of change in diagnosis, planned management, and treatment after PET scan results in this subgroup of patients (online suppl. tables 5, 6) was similar to that described above for the overall AUClike cohort.

\section{Discussion}

We have previously reported that amyloid PET information can lead to changes in the diagnosis and intended management of patients undergoing or recently having completed an evaluation for cognitive decline [17]. Although our study restricted enrollment to patients with diagnostic uncertainty expected to benefit from an amyloid PET scan, it was conducted prior to florbetapir approval in 2012, and our entry criteria were different and possibly less restrictive than the subsequently published AUC guidelines [22]. Thus, the primary goal of the present reanalysis was to determine whether our previous conclusions remained valid for the subset of patients meeting a strict interpretation of the AUC. The results suggest that, if anything, the impact of amyloid PET information is amplified in the AUC-like cohort.

The rate of change in diagnostic thinking was significantly higher for AUC-like subjects compared to non-AUC subjects (62 vs. $45 \%$; table 3 ). These differences were largely attributable to the classification of the probable AD patients as part of the non-AUC cohort. The probable AD patients ( 30 of 104 non-AUC subjects) had a predictable, high incidence of amyloid-positive scans (73\%; table 1), which was consistent with the prescan diagnosis and did not result in a change in diagnosis after scanning (table 3; online suppl. table 2). In contrast, the majority of AUC-like patients had indeterminate diagnoses, and $68 \%$ of them had a changed diagnosis after the PET scan (i.e., to AD etiology after a positive scan or to non-AD etiology after a negative scan; online suppl. table 2).

Similarly, the previously reported [17] impact of PET scan information on intended patient management was not diminished but, if anything, enhanced in the AUC-like cohort. Overall, changes in management plans were high for both the AUC-like and the non-AUC cohort (88 
and $86 \%$, respectively). Planned treatment with $\mathrm{AD}$ medications changed in a direction consistent with the PET scan result, with larger changes noted in the AUC-like than in the non-AUC cohort (table 4). This difference may be driven by the clinically diagnosed typical $\mathrm{AD}$ patients in the non-AUC cohort. These subjects had a high rate of AD medication use/ intended use at baseline, leaving less room for increases after a positive scan. Moreover, physicians may have been hesitant to remove therapy from amyloid-negative demented subjects previously diagnosed as having AD, with the result that approximately $20 \%$ of the AUC-like and $30 \%$ of the non-AUC subjects were slated to remain on AD medications after a negative amyloid scan. This latter result may suggest that physicians were using the amyloid PET information in the context of the patient's overall presentation and considering that medications such as cholinesterase inhibitors might benefit some subjects with dementias of non-AD origin [25]. However, additional studies could be valuable in enabling evidence-based decisions on treatment efficacy in patient populations defined by both clinical presentation and amyloid status.

Among the subjects with an incomplete workup at study entry (group B), both positive and negative scans led to reductions in planned neuropsychological testing, structural imaging, and lumbar punctures, and, again, this effect was numerically greater in AUC-like than in non-AUC subjects.

In the absence of a control group that did not receive PET scan results, it is difficult to evaluate the finding that planned diagnostic testing decreased after both positive and negative scans. This result may simply be an indication that the prescan management plans overestimated what physicians would have done had they not received the PET scan information. Alternatively, it may reflect the relatively small range of situations where additional testing would provide decisive information beyond that obtained from the amyloid scan. For example, following an amyloid-positive PET scan, additional assessments such as neuropsychological tests (to better establish the nature of the clinical deficit), FDGPET (to identify a frontotemporal dementia-like pattern of brain metabolism), DaTScan SPECT (to identify dopamine neuronal dysfunction characteristic of dementia with Lewy bodies/Parkinson's disease $)$, or CSF analysis $\left(\mathrm{A} \beta_{42}\right.$, to confirm the amyloid PET result, and tau, which might be elevated in AD but not in the alternative conditions) might be warranted for cases with 'atypical' clinical features that suggest a non-AD diagnosis. However, in the absence of such characteristic symptoms (i.e., the majority of subjects in this study), the risk is low that these alternative pathophysiologies are responsible for the cognitive impairments.

Similarly, an amyloid-negative PET scan is inconsistent with a diagnosis of AD. In cases where characteristic symptoms suggest that a diagnosis such as cerebrovascular disease, frontotemporal dementia, or dementia with Lewy bodies/Parkinson's disease is present, a negative scan may be sufficient to support such a non-AD diagnosis by excluding AD as the main viable alternative, and additional testing may not be required. Moreover, in the absence of characteristic symptoms of a non-AD dementia, emerging data [26, 27] suggest that the majority of patients will experience minimal cognitive deterioration over 2-3 years of follow-up. Thus, watchful waiting, combined with treatment for potential nondegenerative factors (depression, vascular disease) might be the best approach. 
Perhaps the most controversial reduction in diagnostic testing after amyloid PET was the elimination of structural imaging in more than half of the patients (30/56) for whom it was originally planned. Structural imaging is almost always recommended as part of a dementia workup [2, 22-24]. The study did not record a rationale for change in intended management. However, it can be speculated that the investigators were attempting to balance cost and burden to the patient against the potential that sufficient information would be gained to change the diagnosis or management. In the case of an amyloid-positive scan, the investigator may have decided it to be unlikely that structural images would reveal a mass or sufficient cerebrovascular disease to steer away from a diagnosis of AD etiology. In the case of amyloidnegative subjects, many of whom had very mild impairments, the investigators may have decided on a course of watchful waiting as discussed above. It is also worth noting that many of the scans in this study were done on PET CT scanners. Although the amyloid PET result was interpreted centrally, the images were available locally for safety review and could be shared with the treating physician. Hence, in some cases structural information may have been available from the attenuation CT performed during the PET scan and may have been sufficient to rule out the presence of significant masses or infarcts.

To our knowledge, this is the first study to evaluate the impact of AUC on the relationship of PET scan outcomes to diagnosis and management plans regarding subjects with a history of cognitive decline. A limitation of our study is that the AUC were published after our study was conducted and the AUC were applied retrospectively; this could have led to some misclassification of AUC-like and non-AUC cases. However, if anything, our classification was conservative. The differences between AUC-like and non-AUC cases might be even greater in other settings where no diagnostic uncertainty might exist for the non-AUC group. For example, we classified patients given working diagnoses of 'not related to AD' as nonAUC cases. But by the entry criteria, physicians needed to express an at least $15 \%$ likelihood that these cases had AD etiology and be less than $85 \%$ certain of the working diagnosis. Thus, these could have been considered possible AD cases, and thus be classed as AUC-like. More than half of these clinically diagnosed non-AD cases were amyloid positive on florbetapir PET, but we would expect a lower percentage of amyloid positives in a welldocumented population of non-AD patients [20]. Similarly, we classified cases with a working diagnosis of MCI due to $\mathrm{AD}$ as non-AUC cases, but less than half of these cases were found to be positive for amyloid on the PET scan (49 vs. $73 \%$ for typical AD dementia/ probable $\mathrm{AD}$ ). It is possible that a higher amyloid-positive rate could be observed in cases for which there were additional data to support a typical amnestic MCI or AD presentation, and for which the physicians expressed high diagnostic confidence. However, cases like these subjects for whom physicians expressed less than $85 \%$ confidence in an MCI-AD diagnosis might better be considered unexplained MCI for the purposes of an AUC classification.

As noted above, the RCR-RCP and IIWG guidelines differ from the AIT-AUC primarily by specifying that structural imaging, and in some cases FDG-PET, be performed prior to amyloid imaging. Fewer than $10 \%$ of the patients in this study had undergone FDG-PET at screening. However, $67 \%$ of the subjects overall and $75 \%$ of the AUC-like subjects had previously undergone structural imaging. The pattern of change in diagnosis, management plan, and treatment in this subgroup of AUC-like patients was similar to that for the overall 
group of AUC subjects without previous MRI, with the possible exception that subjects with previous structural imaging appeared more likely to change from an indeterminate to a non$\mathrm{AD}$ diagnosis after a negative scan. An important limitation of this analysis is that patients were not randomized to receive or not receive MRI. The decision to obtain an MRI prior to amyloid PET was made by the diagnosing physician and was likely influenced by practice habits and the severity and complexity of the case at presentation. Thus, the present data cannot be used to assess the value of placing MRI (or any other diagnostic test) ahead of the PET scan in the diagnostic algorithm; the present data do not allow us to assess the percentage of patients for whom diagnostic dilemmas resolve after MRI testing. However, these data do suggest that there exist patients who meet both the AIT and IIWG AUC, having residual diagnostic uncertainty even after an MRI, and who benefit from amyloid imaging, as demonstrated by changes in diagnosis, planned testing, and treatment after receiving PET scan results.

Although this study is possibly the first to evaluate the impact of amyloid imaging in the context of the proposed AUC, key conclusions from this study are consistent with those from the previous literature and should be generalizable to other populations. Specifically, the AUC excludes cases where there is a high a priori relationship between the diagnosis and amyloid status, notably dementia with typical AD presentation (probable AD, 73\% positive) and cognitive decline of limited duration or cases lacking objective evidence of impairment ( $71 \%$ negative), and focusses on cases of indeterminate or mixed etiology, where amyloid status is likely to be more difficult to predict a priori. The finding that the proportion of amyloid-positive cases increases with disease severity along the spectrum of suspected $\mathrm{AD}$ patients is consistent with an extensive literature [26-29]. This may explain the difference in the proportion of amyloid-positive cases and the difference in the proportion of cases with diagnostic change among previous studies that have compared scan effects in wellcharacterized, diagnosed subjects (e.g., AD vs. healthy controls [21] or AD vs. frontotemporal dementia [20]) and the effect in memory clinic patients [16, 18, 19]. The current finding that diagnostic change is also more likely in the diagnostically indeterminate AUC-like cases than in the more certain probable AD cases is also consistent with reports that change is more likely in situations of lower diagnostic confidence or greater uncertainty $[19,20]$. Finally, the current results are consistent with all available previous studies, showing an impact of amyloid PET results on patient management planning and treatment with $\mathrm{AD}$ therapeutics $[17,20,21]$ and further suggesting that differences in the magnitude of the effect may be related to where the study patients fall along the AUC-like versus nonAUC spectrum.

In conclusion, amyloid imaging results altered diagnostic thinking in both AUC-like cases and in cases with diagnostic uncertainty that did not meet a conservative interpretation of the proposed criteria. The amyloid imaging results led to high rates of management change regardless of AUC status, although these changes tended to be modestly higher in AUC-like patients. A refinement of the AUC guidelines to include patients with a clinical diagnosis of MCI due to AD for whom there remains significant diagnostic uncertainty might be considered in future revisions of the AUC, since clinicians appear to have difficulty rendering this diagnosis accurately without amyloid biomarker data. 


\section{Supplementary Material}

Refer to Web version on PubMed Central for supplementary material.

\section{Acknowledgement}

This study was sponsored by Avid Radiopharmaceuticals, a wholly owned subsidiary of Eli Lilly and Company.

\section{Appendix}

The ${ }^{18}$ F-AV-45-A17Study Group

USA: Dr. John Miliziano, Morton Plant Hospital, Clearwater, Fla.; Dr. Anil Nair, Sheela Chandrashekar, and Nicole Chan, Alzheimer's Disease Center, Quincy Medical Center, Quincy, Mass.; Dr. Upinder Singh, Geriatric Solutions, LLC, Las Vegas, Nev.; Dr. Ralph Edward Coleman, Dr. P. Murali Doraiswamy, Dr. James R. Burke, and Dr. Terence Z. Wong, Duke University, Durham, N.C.; Dr. Atul Syal, Arizona Neurological Institute, PC, Sun City, Ariz.; Dr. Frederick Warren Schaerf, Neuropsychiatric Research Center of Southwest Florida, Fort Myers, Fla.; Dr. Ebrahim Delpassand, Excel Diagnostic and Nuclear Oncology Center, Houston, Tex.; Dr. Adam Fleisher, Dr. Roy Yaari, and Candy Monarrez, Banner Alzheimer's Institute, Phoenix, Ariz.; Dr. Stephen Bunker, Fusion Diagnostic Group/ Hampton Health, Ltd., San Francisco, Calif.; Dr. James Clifton Patterson II, Louisiana State University Health Sciences Center, Department of Psychiatry, Shreveport, La.; Dr. Craig Sherman, Manhattan Diagnostic Radiology, New York, N.Y.; Dr. Stephen Salloway and Cheryl Cordeiro, Butler Hospital, Providence, R.I.; Dr. Carl Sadowsky and Dr. Teresa Villena, Premiere Research Institute at Palm Beach Neurology, West Palm Beach, Fla.; Dr. Stewart Edmunds, Greensboro Radiology, PA/Guilford Neurologic Associates, Greensboro, N.C.; Dr. Jonathan Wiener, Diagnostic Centers of America, Delray Beach, Fla.; Dr. Marwan Sabbagh, Banner Research Institute, Sun City, Ariz.; Dr. Paul Brownstone, Alpine Clinical Research Center, Inc., Boulder, Colo.; Dr. Brian Ott, Rhode Island Hospital, Alzheimer's Disease and Memory Disorders Center, Providence, R.I.; Dr. Alan Fischman, Shriners Hospitals for Children, Boston, Mass./South Shore Neurologic Associates, Patchogue, N.Y.

\section{References}

1. McKhann G, Drachman D, Folstein M, Katzman R, Price D, Stadlan EM: Clinical diagnosis of Alzheimer's disease: report of the NINCDS-ADRDA Work Group under the auspices of Department of Health and Human Services Task Force on Alzheimer's Disease. Neurology 1984;34:939-944. [PubMed: 6610841]

2. McKhann GM, Knopman DS, Chertkow H, Hyman BT, Jack CR, Kawas CH, Klunk WE, Koroshetz WJ, Manly JJ, Mayeux R, Mohs RC, Morris JC, Rossor MN, Scheltens P, Carrillo MC, Thies B, Weintraub S, Phelps CH: The diagnosis of dementia due to Alzheimer's disease: recommendations from the National Institute on Aging- Alzheimer's Association workgroups on diagnostic guidelines for Alzheimer's disease. Alzheimers Dement 2011;7:263-269. [PubMed: 21514250]

3. Beach TG, Monsell SE, Phillips LE, Kukull W: Accuracy of the clinical diagnosis of Alzheimer disease at National Institute on Aging Alzheimer Disease Centers, 2005-2010. J Neuropathol Exp Neurol 2012;71:266-273. [PubMed: 22437338]

4. Serrano-Pozo A, Qian J, Monsell SE, Blacker D, Gomez-Isla T, Betensky RA, Growdon JH, Johnson KA, Frosch MP, Sperling RA, Hyman BT: Mild to moderate Alzheimer dementia with insufficient neuropathological changes. Ann Neurol 2014;75:597-601. [PubMed: 24585367] 
5. Klunk WE, Engler H, Nordberg A, Wang Y, Blomqvist G, Holt DP, Bergström M, Savitcheva I, Huang GF, Estrada S, Ausén B, Debnath ML, Barletta J, Price JC, Sandell J, Lopresti BJ, Wall A, Koivisto P, Antoni G, Mathis CA, Långström B: Imaging brain amyloid in Alzheimer's disease with Pittsburgh Compound-B. Ann Neurology 2004; 55:306-319.

6. Rowe CC, Ackerman U, Browne W, Mulligan R, Pike KL, O'Keefe G, Tochon-Danguy H, Chan G, Berlangieri SU, Jones G, Dickinson-Rowe KL, Kung HP, Zhang W, Kung MP, Skovronsky D, Dyrks T, Holl G, Krause S, Friebe M, Lehman L, Lindemann S, Dinkelborg LM, Masters CL, Villemagne VL: Imaging of amyloid beta in Alzheimer's disease with 18F-BAY94-9172, a novel PET tracer: proof of mechanism. Lancet Neurol 2008;7:129-135. [PubMed: 18191617]

7. Nelissen N, Van Laere K, Thurfjell L, Owenius R, Vandenbulcke M, Koole M, Bormans G, Brooks DJ, Vanden-berghe R: Phase 1 study of the Pittsburgh compound B derivative ${ }^{18}$ F-flutemetamol in healthy volunteers and patients with probable Alzheimer disease. J Nucl Med 2009;50:1251-1259. [PubMed: 19617318]

8. Wong DF, Rosenberg PB, Zhou Y, Ross J, Edell S, Kumar A, Raymont V, Ravert HT, Dannals RF, Nandi A, Brasic J, Ye W, Alexander M, Hilton J, Lyketkos C, Kung HF, Joshi AD, Skovronsky DM, Pontecorvo MJ: In vivo imaging of amyloid deposition in Alzheimer disease using the radioligand 18F-AV-45 (florbetapir F 18). J Nucl Med 2010;51:913-920. [PubMed: 20501908]

9. Joshi AD, Pontecorvo MJ, Clark CM, Carpenter AP, Jennings DL, Sadowsky CH, Adler LP, Kovnat KD, Seibyl JP, Saha K, Burns JD: Lowrey MJ, Mintun MA, Skovronsk DM; Florbetapir F 18 Study Investigators: Performance characteristics of amyloid PET with florbetapir F 18 in patients with Alzheimer's disease and cognitively normal subjects. J Nucl Med 2012;53:378-384. [PubMed: 22331215]

10. Clark CM, Schneider JA, Bedell BJ, Beach TG, Bilker WG, Mintun MA, Pontecorvo MJ, Hefti F, Carpenter AP, Flitter ML, Krautkramer MJ, Kung HF, Coleman RE, Doraiswamy PM, Fleischer AS, Sabbagh MN, Sadowsky CH, Reiman PEM, Zehntner SP, Skovronsky DM; AV45-A07 Study Group: Use of florbetapir-PET for imaging $\beta$-amyloid pathology. JAMA 2011;305:275-283. [PubMed: 21245183]

11. Clark CM, Pontecorvo MJ, Beach TG, Bedell BJ, Coleman RE, Doraiswamy PM, Fleisher AS, Reiman PEM, Sabbagh MN, Sadowsky CH, Schneider JA, Arora A, Carpenter AP, Flitter ML, Joshi AD, Krautkramer MJ, Lu M, Mintun MA, Skovronsky DM: Cerebral PET with florbetapir compared with neuropathology at autopsy for detection of neuritic amyloid- $\beta$ plaques: a prospective cohort study. Lancet Neurol 2012;11:669-678. [PubMed: 22749065]

12. Curtis C, Gamez JE, Singh U, Sadowsky CH, Villena T, Sabbagh MN, Beach TG, Duara R, Fleisher AS, Frey KA, Wlaker Z, Hunjan A, Holmes C, Escovar YM, Vera CX, Agronin ME, Ross J, Bozoki A, Akinola M, Shi J, Vandenberghe R, Ikonomovic MD, Sherwin PF, Grachev ID, Farrar G, Smith APL, Buckley CJ, McLain R, Salloway S: Phase 3 trial of flutemetamol labeled with radioactive fluorine 18 imaging and neuritic plaque density. JAMA Neurol 2015;72:287-294. [PubMed: 25622185]

13. Leinonen V, Alafuzoff I, Aalto S, Suotunen T, Savolainen S, Någren K, Tapiola T, Pirttilä T, Rinne J, Jääskeläinen JE, Soininen H, Rinne JO: Assessment of $\beta$-amyloid in a frontal cortical brain biopsy specimen and by positron emission tomography with carbon 11-labeled Pittsburgh Compound B. Arch Neurol 2008;65:1304-1309. [PubMed: 18695050]

14. Sabri O, Sabbagh MN, Seibyl J, Barthel H, Akatsu H, Ouchi Y, Senda K, Murayama S, Ishii K, Takao M, Beach TG, Rowe CC, Leverenz JB, Ghetti B, Ironside JW, Catafau AM, Stephens AW, Mueller A, Koglin N, Hoffmann A, Roth K, Reininger C, Schulz-Schaeffer WJ; Florbetaben Phase 3 Study Group: Florbetaben PET imaging to detect amyloid beta plaques in Alzheimer's disease: phase 3 study. Alzheimers Dement 2015;11:964-974. [PubMed: 25824567]

15. Degerman Gunnarsson M, Lindau M, Santillo AF, Wall A, Engler H, Lannfelt L, Basun H, Kilander L: Reevaluation of clinical dementia diagnoses with Pittsburgh compound B positron emission tomography. Dement Geriatr Cogn Dis Extra 2013;3:472-481. [PubMed: 24516415]

16. Frederiksen KS, Hasselbalch SG, Hejl AM, Law I, Højgaard L, Waldemar G: Added diagnostic value of 11C-PiB-PET in memory clinic patients with uncertain diagnosis. Dement Geriatr Cogn Dis Extra 2012;2:610-621. [PubMed: 23341826]

17. Grundman M, Pontecorvo MJ, Salloway SP, Doraiswamy PM, Fleisher AS, Sadowsky CH, Nair AK, Siderowf A, Lu M, Arora AK, Agbulos A, Flitter ML, Krautkramer MJ, Sarsour K, 
Skovronsky DM, Mintun MA; AV-45-A17 Study Group: Potential impact of amyloid imaging on diagnosis and intended management in patients with progressive cognitive decline. Alzheimer Dis Assoc Disord 2013,27:4-15. [PubMed: 23203162]

18. Mitsis EM, Bender HA, Kostakoglu L, Machac J, Martin J, Woehr JL, Sewell MC, Aloysi A, Goldstein MA, Li C, Sano M, Gandy S: A consecutive case series experience with [18F] florbetapir PET imaging in an urban dementia center: impact on quality of life, decision making, and disposition. Mol Neurodegener 2014;9:10. [PubMed: 24484858]

19. Ossenkoppele R, Prins ND, Pijnenburg YA, Lemstra AW, van der Flier WM, Adriaanse SF, Windhorst AD, Handels RL, Wolfs CA, Aalten P, Verhey FR, Verbeek MM, van Buchem MA, Hoekstra OS, Lammertsma AA, Scheltens P, van Berckel BN: Impact of molecular imaging on the diagnostic process in a memory clinic. Alzheimers Dement 2013;9:414-421. [PubMed: 23164552]

20. Sanchez-Juan P, Ghosh PM, Hagen J, Gesierich B, Henry M, Grinberg LT, O'Neil JP, Janabi M, Huang EJ, Trojanowski JQ, Vinters HV, Gorno-Tempini M, Seeley WW, Boxer AL, Rosen HJ, Kramer JH, Miller BL, Jagust WJ, Rabinovici GD: Practical utility of amyloid and FDG-PET in an academic dementia center. Neurology 2014; 82:230-238. [PubMed: 24353340]

21. Schipke CG, Peters O, Heuser I, Grimmer T, Sabbagh MN, Sabri O, Hock C, Kunz M, Kuhlmann J, Reininger C, Blankenburg M: Impact of $\beta$-amyloid-specific florbetaben PET imaging on confidence in early diagnosis of Alzheimer's disease. Dement Geriatr Cogn Disord 2012;33:416422. [PubMed: 22814208]

22. Johnson KA, Minoshima S, Bohnen NI, Donohue KJ, Foster NL, Herscovitch P, Karlawish JH, Rowe CC, Carrillo MC, Hartley DM, Hedrick S, Pappas V, Thies WH: Appropriate use criteria for amyloid PET: a report of the Amyloid Imaging Task Force, the Society of Nuclear Medicine and Molecular Imaging, and the Alzheimer's Association. Dual publication in: Alzheimers Dement 2013;9:e-1-16 and J Nucl Med 2013;54:476-490. [PubMed: 23359661]

23. Royal College of Physicians and Royal College of Radiologists: Evidence-Based Indications for the Use of PET-CT in the UK. London, RCP/RCR, 2013.

24. Guerra UP, Nobili FM, Padovani A, Perani D, Pupi A, Sorbi S, Trabucchi M: Recommendations from the Italian Interdisciplinary Working Group (AIMN, AIP, SINDEM) for the utilization of amyloid imaging in clinical practice. Neurol Sci 2015;36:1075-1081. [PubMed: 25616445]

25. Roman GC, Salloway S, Black SE, Royall DR, DiCarli C, Weiner MW, Moline M, Kumar D, Schindler R, Posner H: Randomized, placebo-controlled, clinical trial of donepezil in vascular dementia: differential effects by hippocampal size. Stroke 2010;41:1213-1221. [PubMed: 20395618]

26. Doraiswamy PM, Sperling RA, Johnson K, Reiman EM, Wong TZ, Sabbagh MN, Sadowsky CH, Fleisher AS, Carpenter A, Joshi AD, Lu M, Grundman M, Mintun MA, Skovronsky DM, Pontecorvo MJ; AV45-A11 Study Group: Florbetapir F 18 amyloid PET and longitudinal cognitive decline: a prospective 36-month multicenter study. Mol Psychiatry 2014;19:1044-1051. [PubMed: 24614494]

27. Lim YY, Maruff P, Pietrzak RH, Ames D, Ellis KA, Harrington K, Lautenschlager NT, Szoeke C, Martins RN, Masters CL, Villemagne VL, Rowe CC; AIBL Research Group: Effect of amyloid on memory and non-memory decline from preclinical to clinical Alzheimer's disease. Brain 2014;137:221-231. [PubMed: 24176981]

28. Rowe CC, Ellis KA, Rimajova M, Bourgeat P, Pike KE, Jones G, Fripp J, Tochon-Danguy H, Morandeau L, O’Keefe G, Price R, Raniga P, Robins P, Acosta O, Lenzo N, Szoeke C, Salvado O, Head R, Martins R, Masters CL, Ames D, Villemagne VL: Amyloid imaging results from the Australian Imaging, Biomarkers and Lifestyle (AIBL) study of aging. Neurobiol Aging 2010;31:1275-1283. [PubMed: 20472326]

29. Vandenberghe R, Van Laere K, Ivanoiu A, Salmon E, Bastin C, Triau E, Hasselbalch S, Law I, Andersen A, Korner A, Minthon L, Garraux G, Nelissen N, Bormans G, Buckley C, Owenius R, Thurfjell L, Farrar G, Brooks DJ: ${ }^{18}$ F-flutemetamol amyloid imaging in Alzheimer disease and mild cognitive impairment: a phase 2 trial. Ann Neurol 2010;68:319-329. [PubMed: 20687209] 


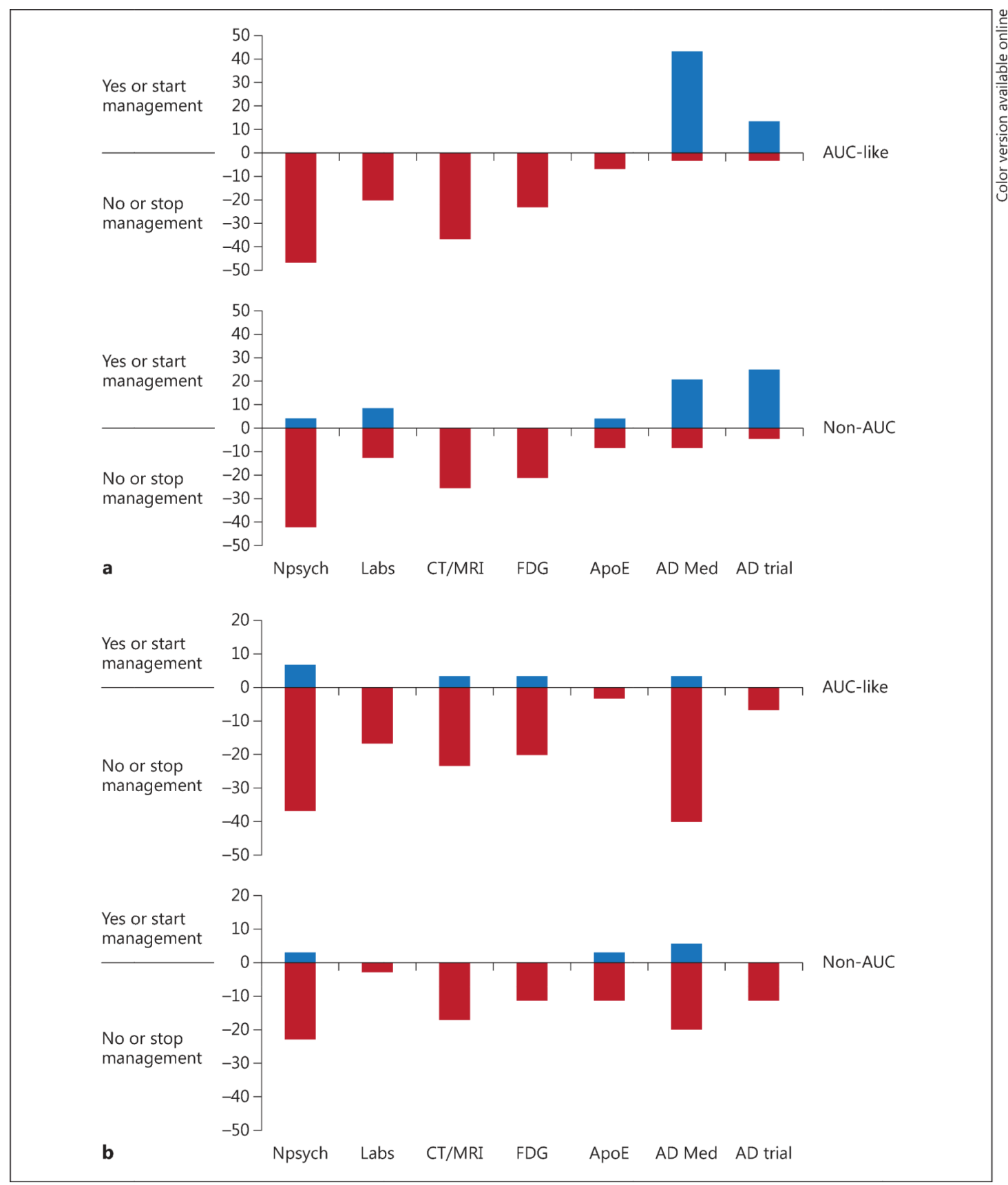

Fig. 1.

Impact of an $\mathrm{A} \beta 1+(\mathbf{a})$ and an $\mathrm{A} \beta$ - florbetapir PET scan (b) on proposed management plan changes in patients with incomplete workup at study entry (group B), shown as a function of AUC status (AUC-like or non-AUC). Values represent the percentages of patients in the respective population group with an increase (blue) or decrease (red; colors refer to the online version only) in intended use of a diagnostic test or treatment after PET scanning. Thus, for example, the top half of a shows that plans for additional neuropsychological testing were eliminated after PET scan results became known in more than $40 \%$ of group B (AUC-like patients with a positive scan), and plans for treatment with cholinesterase 
medication or memantine were added for more than $40 \%$ of the same patients. The bottom half of a shows directionally similar, but numerically smaller, trends in the non-AUC group. b By comparison with a positive PET scan, after a negative PET scan there were numerically smaller decreases in planned diagnostic testing and net decreases in planned use of cholinesterase medications. Npsych $=$ Neuropsychological testing; Labs $=$ any laboratory analysis of blood or urine samples performed to aid in dementia diagnosis including but not limited to tests for vitamin $\mathrm{B}_{12}$ levels, thyroid function, or syphilis serology; FDG = FDGPET $;$ AopE $=$ apolipoprotein E; AD Med = cholinesterase medication or memantine . 
Table 1.

AUC classification by diagnosis

\begin{tabular}{|c|c|c|c|c|}
\hline & \multicolumn{2}{|c|}{$\underline{\text { AUC-like }}$} & \multicolumn{2}{|c|}{ Non-AUC } \\
\hline & $\mathbf{n}$ & $\mathbf{A} \beta+, \%$ & $\mathbf{n}$ & $\mathbf{A} \beta+, \%$ \\
\hline \multicolumn{5}{|l|}{ Due to $A D(n=86)$} \\
\hline Atypical AD & 10 & $70^{a}$ & 0 & 0 \\
\hline Lewy body disease with $\mathrm{AD}$ (amyloid) pathology & 3 & $33.3^{a}$ & 0 & 0 \\
\hline Mixed dementia with $\mathrm{AD}$ & 8 & $75^{a}$ & 0 & 0 \\
\hline Probable AD or dementia of the Alzheimer's type & 0 & 0 & 30 & 73.3 \\
\hline Prodromal $\mathrm{AD}$ or $\mathrm{MCI}$ due to $\mathrm{AD}$ & 0 & 0 & 35 & 48.6 \\
\hline Total due to $\mathrm{AD}$ & 21 & 66.7 & 65 & 60.0 \\
\hline \multicolumn{5}{|l|}{ Syndromic/indeterminate $(n=122)$} \\
\hline Dementia of uncertain etiology & 22 & 63.6 & 0 & 0 \\
\hline Memory complaints or progressive cognitive decline, uncertain origin & 19 & 31.6 & 17 & $35.3^{b}$ \\
\hline MCI of uncertain etiology & 57 & 36.8 & 7 & $14.3^{b}$ \\
\hline Total syndromic/indeterminate & 98 & 41.8 & 24 & 29.2 \\
\hline \multicolumn{5}{|l|}{ Not due to $A D(n=21)$} \\
\hline Alcohol-related dementia & 0 & 0 & 1 & 0 \\
\hline Corticobasal degeneration & 0 & 0 & 1 & 0 \\
\hline Dementia of uncertain etiology (but not AD) & 2 & $100^{c}$ & 1 & 100 \\
\hline Frontotemporal dementia & 2 & $50^{c}$ & 3 & 33.3 \\
\hline MCI etiology uncertain (but not AD) & 1 & $0^{c}$ & 0 & 0 \\
\hline Mixed dementia with $\mathrm{AD}$ & 1 & $100^{c}$ & 0 & 0 \\
\hline Psychiatric: depression & 0 & 0 & 1 & 100 \\
\hline Structural (stroke, brain tumor, hydrocephalus, brain trauma) & 0 & 0 & 1 & 100 \\
\hline Vascular disease & 0 & 0 & 7 & 57.1 \\
\hline Total not due to $\mathrm{AD}$ & 6 & 66.7 & 15 & 53.3 \\
\hline
\end{tabular}

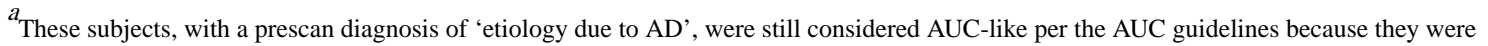
considered to have an atypical $\mathrm{AD}$ presentation or $\mathrm{AD}$ mixed with other pathologies.

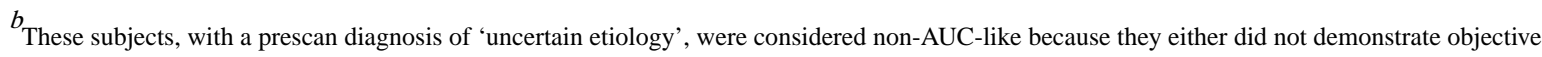
cognitive impairment or were impaired for less than 6 months.

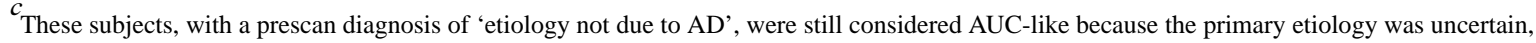
they were less than 65 years of age, or they were considered to have a mixed type of dementia. 
Table 2.

Demographics and baseline characteristics

\begin{tabular}{lccc}
\hline & AUC-like (n= 125) & Non-AUC (n = 104) & Total (n = 229) \\
\hline Age, years & $73.5 \pm 8.18$ & $74.9 \pm 7.92$ & $74.1 \pm 8.07$ \\
Female & $58(46.4)$ & $56(53.8)$ & $114(49.8)$ \\
Caucasian & $115(92.0)$ & $102(98.1)$ & $217(94.8)$ \\
Education, years & $14.6 \pm 2.72$ & $14.7 \pm 2.62$ & $14.6 \pm 2.67$ \\
MMSE score & $24.7 \pm 5.07$ & $25.3 \pm 4.31$ & $25.0 \pm 4.74$ \\
Dementia status & & & \\
$\quad$ Demented & $45(36.0)$ & $38(36.5)$ & $83(36.2)$ \\
$\quad$ Nondemented & $80(64.0)$ & $66(63.5)$ & $146(63.8)$ \\
Prescan clinical diagnosis & & & \\
$\quad$ Etiology due to AD & $21(16.8)$ & $65(62.5)$ & $86(37.6)$ \\
Etiology not due to AD & $6(4.8)$ & $15(14.4)$ & $21(9.2)$ \\
Syndromic & $98(78.4)$ & $24(23.1)$ & $122(53.3)$ \\
Physician type & & & \\
Geriatrician & $16(12.8)$ & $10(9.6)$ & $26(11.4)$ \\
Neurologist & $94(75.2)$ & $84(80.8)$ & $178(77.7)$ \\
Psychiatrist & $15(12.0)$ & $10(9.6)$ & $25(10.9)$ \\
Months since symptom onset & $36.9 \pm 38.86$ & $40.7 \pm 37.50$ & $38.6 \pm 38.21$ \\
\hline
\end{tabular}

Values are presented as $\mathrm{n}(\%)$ or mean $\pm \mathrm{SD}$. 
Table 3.

Change in diagnosis after receipt of florbetapir scan results

\begin{tabular}{|c|c|c|c|c|c|}
\hline & \multirow[t]{2}{*}{ Prescan diagnosis } & \multicolumn{3}{|c|}{ Postscan diagnosis, n (\%) } & \multirow[t]{2}{*}{ Change in diagnosis } \\
\hline & & Due to AD & Indeterminate & Not due to AD & \\
\hline \multicolumn{6}{|l|}{ AUC-like } \\
\hline \multirow{3}{*}{$\begin{array}{l}\text { Amyloid-negative } \\
\text { subjects }(n=66)\end{array}$} & due to $\mathrm{AD}(\mathrm{n}=7)$ & 0 & 0 & $7(100.0)$ & $7 / 7(100.0)$ \\
\hline & indeterminate $(\mathrm{n}=57)$ & 0 & $30(52.6)$ & $27(47.4)$ & $27 / 57(47.4)$ \\
\hline & not due to $\mathrm{AD}(\mathrm{n}=2)$ & 0 & 0 & $2(100.0)$ & $0 / 2(0.0)$ \\
\hline \multirow{3}{*}{$\begin{array}{l}\text { Amyloid-positive } \\
\text { subjects }(n=59)\end{array}$} & due to $\mathrm{AD}(\mathrm{n}=14)$ & $14(100.0)$ & 0 & 0 & $0 / 14(0.0)$ \\
\hline & indeterminate $(n=41)$ & $40(97.6)$ & $1(2.4)$ & 0 & $40 / 41(97.6)$ \\
\hline & not due to $\mathrm{AD}(\mathrm{n}=4)$ & $4(100.0)$ & 0 & 0 & $4 / 4(100.0)$ \\
\hline Total & & & & & $78 / 125(62.4)$ \\
\hline \multicolumn{6}{|l|}{ Non-AUC } \\
\hline \multirow{3}{*}{$\begin{array}{l}\text { Amyloid-negative } \\
\text { subjects }(n=50)\end{array}$} & due to $\mathrm{AD}(\mathrm{n}=26)$ & $1(3.8)$ & $22(84.6)$ & $3(11.5)$ & $25 / 26(96.2)$ \\
\hline & indeterminate $(\mathrm{n}=17)$ & $0(0.0)$ & $11(64.7)$ & $6(35.3)$ & $6 / 17(35.3)$ \\
\hline & not due to $\mathrm{AD}(\mathrm{n}=7)$ & $0(0.0)$ & $1(14.3)$ & $6(85.7)$ & $1 / 7(14.3)$ \\
\hline \multirow{3}{*}{$\begin{array}{l}\text { Amyloid-positive } \\
\text { subjects }(n=54)\end{array}$} & due to $\mathrm{AD}(\mathrm{n}=39)$ & $39(100.0)$ & $0(0.0)$ & $0(0.0)$ & $0 / 39(0.0)$ \\
\hline & indeterminate $(\mathrm{n}=7)$ & $7(100.0)$ & $0(0.0)$ & $0(0.0)$ & $7 / 7(100.0)$ \\
\hline & not due to $\mathrm{AD}(\mathrm{n}=8)$ & $8(100.0)$ & $0(0.0)$ & $0(0.0)$ & $8 / 8(100.0)$ \\
\hline Total & & & & & $47 / 104(45.2)$ \\
\hline
\end{tabular}


Table 4.

Impact of a positive $(A \beta+)$ and negative $(A \beta-)$ florbetapir PET scan on intended use of AD medications

\begin{tabular}{llllll}
\hline & AUC-like & & & Non-AUC \\
\cline { 2 - 3 } \cline { 5 - 6 } & $\mathbf{A} \boldsymbol{\beta}+(\mathbf{n}=\mathbf{5 9})$ & $\mathbf{A} \boldsymbol{\beta}-(\mathbf{n}=\mathbf{6 6})$ & & $\mathbf{A} \boldsymbol{\beta}+(\mathbf{n}=\mathbf{5 4})$ & $\mathbf{A} \boldsymbol{\beta}-(\mathbf{n}=\mathbf{5 0})$ \\
\hline Before scanning & 50.8 & 50.0 & 72.2 & 46.0 \\
After scanning & 72.9 & 22.7 & 83.3 & 30.0 \\
\hline
\end{tabular}

Numbers reflect the percentages of patients for whom physicians reported plans to prescribe a cholinesterase inhibitor and/or memantine. 